\title{
ANÁLISE SITUACIONAL DA QUALIDADE DE ÁGUA SUBTERRÂNEA ORIUNDA DE POÇOS DA REGIÃO METROPOLITANA DE FORTALEZA, CEARÁ, BRASIL
}

\author{
Antonia Diana Alves BEZERRA ${ }^{1 *}$, Janelane Coelho da ROCHA ${ }^{3,4}$, Elcivania Rodrigues NOGUEIRA ${ }^{2}$, Dálete \\ Maria Lima de SOUSA ${ }^{2}$, Francisco Gabriel Dias Mota ARAÚJO' ${ }^{1}$, Maíra Gadelha Alves BRANDÃO ${ }^{1,4}$ \& \\ Lydia Dayanne Maia PANTOJA ${ }^{1}$
}

1 Universidade Estadual do Ceará, Fortaleza, Ceará, Brasil.

2 Universidade Federal do Ceará, Fortaleza, Ceará, Brasil.

3 Instituto Federal de Educação, Ciência e Tecnologia do Ceará, Limoeiro do Norte, Ceará, Brasil.

4 Superintendência Estadual do Meio Ambiente, Fortaleza, Ceará, Brasil.

*Autor para correspondência: diannabezerra13@yahoo.com.br

DOI: http://dx.doi.org/10.18571/acbm.158

\section{RESUMO}

A presente pesquisa objetivou realizar análise da qualidade físico-química de água subterrânea de poços da Região Metropolitana de Fortaleza, Ceará. Para isso, foram analisadas 30 amostras de poços oriundos das cidades de Fortaleza, Horizonte, Aquiraz, São Gonçalo do Amarante e Eusébio - CE. As amostras foram coletadas e analisadas por profissionais do laboratório da Superintendência Estadual do Meio Ambiente - SEMACE. Os parâmetros físicoquímicos determinados foram: $\mathrm{pH}$, cor aparente, turbidez, condutividade elétrica, sólidos totais dissolvidos, dureza, alcalinidade total, cálcio, magnésio, cloreto, sódio, potássio, nitrito, nitrato, amônia, ferro e sulfato. Os resultados obtidos foram comparados com os padrões de potabilidade preconizados pela Portaria 2.914/11 do Ministério da Saúde, e revelaram que 63,33\% das amostras analisadas não atenderam ao padrão de potabilidade. Os parâmetros que se mostraram em desacordo foram: $\mathrm{pH}(23,33 \%)$, cor aparente $(20,0 \%)$, turbidez $(16,66 \%)$, sólidos totais dissolvidos $(3,33 \%)$, dureza $(3,33 \%)$, cloretos $(3,33 \%)$, sódio $(3,33 \%)$, nitrato $(40,0 \%)$, amônia $(6,66 \%)$, ferro $(6,66 \%)$ e sulfato $(3,33 \%)$. Diante dos resultados obtidos é recomendado o monitoramento da qualidade da água subterrânea da Região Metropolitana de Fortaleza - CE, bem como os dados apresentados visam auxiliar no panorama da qualidade de água subterrânea da Região Nordeste e, por conseguinte, na garantia da potabilidade das águas subterrâneas na perspectiva nacional.

Palavras-chave: Águas subterrâneas; Monitoramento da água; Potabilidade.

\begin{abstract}
The present study involved analysis of the physico-chemical quality of groundwater from wells located in the Fortaleza Metropolitan Region in the state of Ceará. For this purpose, 30 samples were collected and analyzed from wells in the cities of Fortaleza, Horizonte, Aquiraz, São Gonçalo do Amarante and Eusébio, by laboratory technicians of the State Environmental Superintendency (SEMACE). The parameters determined were: $\mathrm{pH}$, apparent color, turbidity, electrical conductivity, total dissolved solids, hardness, total alkalinity, and levels of calcium, magnesium, chloride, sodium, potassium, nitrite, nitrate, ammonia, iron and sulfate. The results obtained were compared to the potability standards established by Edict 2,914/2011 from the Brazilian Ministry of Health, and revealed that $63.33 \%$ of the samples did not meet the potability standards in at least one aspect. The parameters that were not in compliance were: $\mathrm{pH}(23.33 \%)$, apparent color $(20.0 \%)$, turbidity $(16.66 \%)$, total dissolved solids $(3.33 \%)$, hardness $(3.33 \%)$, chloride $(3.33 \%)$, sodium $(3.33 \%)$, nitrate $(40.0 \%)$, ammonia $(6.66 \%)$, iron $(6.66 \%)$ and sulfate $(3.33 \%)$. Based on these results, we recommend regular monitoring of the groundwater quality in
\end{abstract}


the Fortaleza Metropolitan Region. The data also can help guide efforts to improve the quality of groundwater in the Northeast region of Brazil, and thus of the country as a whole.

Keywords: Groundwater; Water quality monitoring; Potability.

\section{Introdução}

Os recursos hídricos subterrâneos representam $96 \%$ do total de água doce mundialmente disponível para consumo (BRASIL, 2007). Explorados em quase todos os países, os recursos hídricos subterrâneos são usados para atender a demanda total ou suplementar o abastecimento público, sendo também utilizados em atividades de irrigação, geração de energia, indústria, entre outros (SAMPAIO; FEITOSA, 2014).

Quando comparados aos recursos hídricos superficiais, os subterrâneos apresentam vantagens consideráveis, dentre elas: em geral possuem qualidade superior, reservas com grandes volumes, menor perda por evaporação, baixo custo com infraestrutura, menores impactos ambientais etc (ALBUQUERQUE FILHO et al., 2011). São os processos de filtração e purificação que ocorrem naturalmente durante o percurso de infiltração da água no solo até o armazenamento no aquífero (WHATELY; CAMPANILI, 2016), que tornam a água subterrânea em geral de melhor qualidade que as superficiais.

Apesar de mais protegidas que os recursos superficiais, as águas subterrâneas não estão totalmente isentas de contaminação, de acordo com Silva et al. (2014) as fossas sépticas, a disposição inadequada de resíduos sólidos, os postos combustíveis e a agricultura moderna a qual se utiliza de pesticidas e fertilizantes são fatores responsáveis pela contaminação da água subterrânea por agentes patogênicos (bactérias, vírus e protozoários) e substâncias orgânicas e inorgânicas.

São nas regiões urbanas que as águas subterrâneas se encontram mais contaminadas, isso devido ao grande volume de efluentes domésticos não tratados e a disposição de resíduos sólidos em aterros comuns (LIMA et al., 2015). Nos efluentes domésticos urbanos são encontrados elevados teores de elementos químicos como: carbono orgânico, cloreto, nitrogênio, sódio, magnésio, sulfato, ferro, zinco, cobre e em pequenos teores solventes clorados (HIRATA et al., 2009).

De acordo com dados da Pesquisa Nacional por Amostra de Domicílios do Instituto Brasileiro de Geografia e Estatística, em 2015, no Brasil o índice de domicílios ligados à rede coletora de esgoto chegou a 65,3\% (IBGE, 2016). Ainda segundo a pesquisa, o índice de cobertura desse serviço na região Nordeste foi de apenas $42,9 \%$, se mantendo inferior à média nacional.

No Estado do Ceará, dos municípios atendidos pela Companhia de Água e Esgoto do Ceará - CAGECE, o índice de cobertura do serviço de esgotamento sanitário contempla apenas 40,11\% dos domicílios (CEARÁ, 2017). No que se refere à Região Metropolitana de Fortaleza - CE, menos da metade dos domicílios são ligados à rede geral de esgoto, visto que o percentual é de apenas 48,28\% (IBGE, 2011 apud CEARÁ, 2016).

Uma vez que as águas subterrâneas podem estar contaminadas, os efeitos de tais contaminações persistem durante anos, mesmo que cessada a fonte contaminadora, isso porque nos aquíferos não ocorrem à autodepuração, bem como o processo de renovação das águas ocorre de maneira lenta (LIBÂNEO, 2016). Devido aos elevados custos, a descontaminação dos recursos hídricos subterrâneos acaba sendo considerada inviável (LÖBLER, 2013).

Diante dos longos períodos de estiagem como os que ocorrem no Estado do Ceará, os recursos hídricos subterrâneos tornam-se potenciais fontes alternativas de abastecimento público, porém o déficit no serviço de esgotamento sanitário impacta na qualidade da água de tais recursos. Diante disso, o presente trabalho objetivou avaliar a qualidade físico-química de água subterrânea oriunda de poços da Região Metropolitana de Fortaleza, tendo como padrão de potabilidade os limites preconizados pela Portaria do Ministério da Saúde no 2.914, de 12 de dezembro de 2011, 


\section{Biomedica Brasiliensia}

que dispõe sobre os procedimentos de controle da qualidade da água para consumo humano e seu padrão de potabilidade (BRASIL, 2011).

\section{Material e Métodos}

No período de 2014 a 2017, foram coletadas e analisadas quanto aos parâmetros físicoquímicos 30 amostras de águas subterrâneas provenientes de poços situados em algumas cidades da Região Metropolitana de Fortaleza - CE, sendo quinze amostras oriundas da cidade de Fortaleza, nove de Aquiraz, três de Horizonte, duas de São Gonçalo do Amarante e uma de Eusébio (Figura 1).

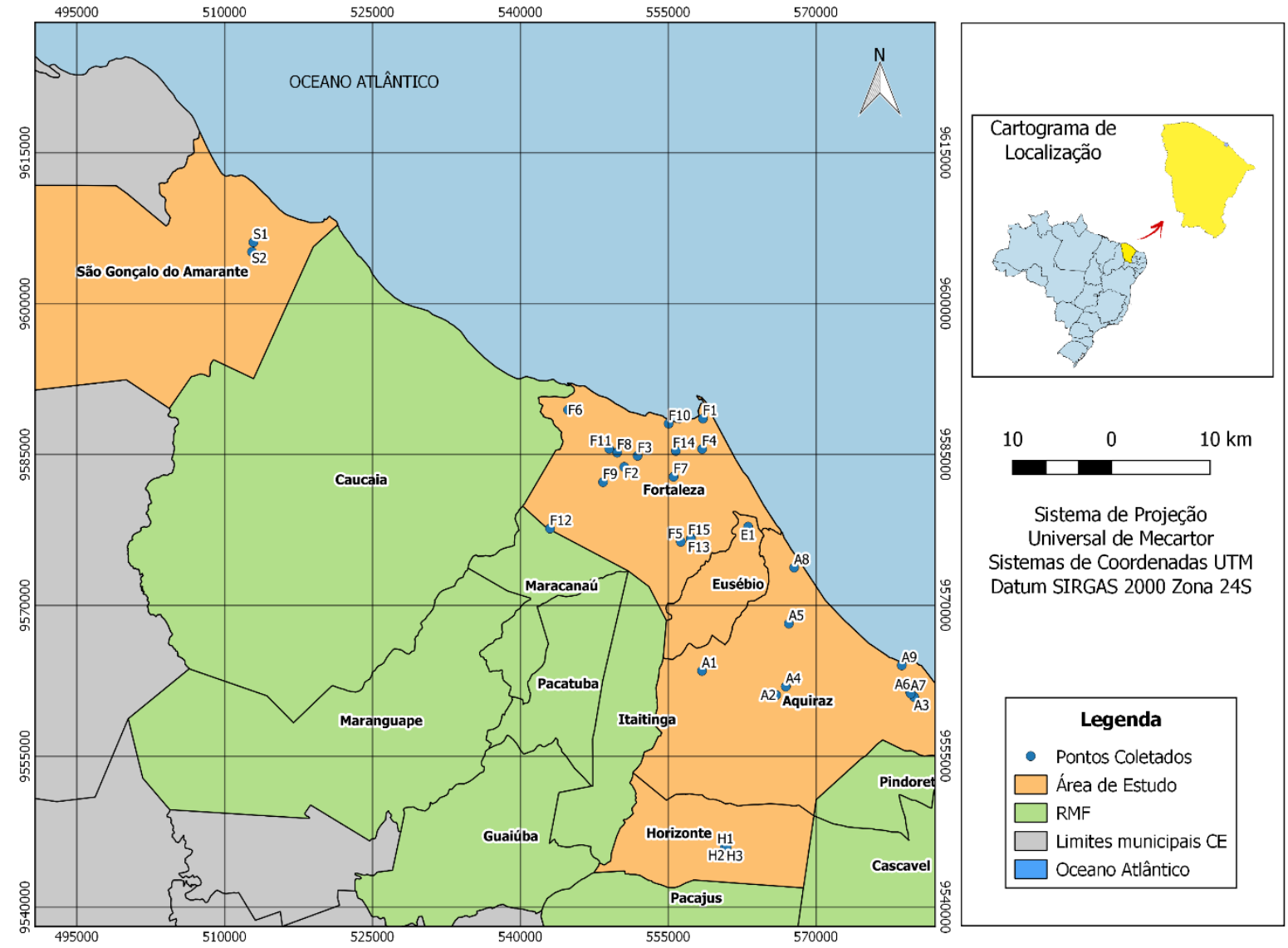

Figura 1. Localização da área de estudo com a distribuição dos poços amostrados por cidades da Região Metropolitana de Fortaleza - CE. Fonte: Os autores. Legenda: RMF - Região Metropolitana de Fortaleza; $\mathrm{F}=$ Fortaleza; $\mathrm{H}=$ Horizonte $; \mathrm{A}=$ Aquiraz; $\mathrm{S}=$ São Gonçalo do Amarante; $\mathrm{E}=$ Eusébio.

As amostras foram coletadas nas torneiras ou canos mais próximos aos poços. Para tanto, foram utilizados frascos de polietileno com capacidade para $2 \mathrm{~L}$ e com tampa vedante. Antes de cada coleta, as torneiras ou canos passaram por assepsia com álcool 70\%, e em seguida deixou-se a água escoar por cerca de 3 minutos, a fim de desprezar a água acumulada na tubulação. Posteriormente, como recomenda a Companhia de Tecnologia de Saneamento Ambiental CETESB (2011) realizou-se a ambientação do frasco, a qual consiste em realizar o enxague do mesmo por cerca de três vezes com a própria amostra.

Depois de coletadas e identificadas, as amostras foram acondicionadas em caixa térmica contendo gelo, e então encaminhadas para serem analisadas por profissionais do laboratório de análises de água e efluentes da Superintendência Estadual do Meio Ambiente - Fort/CE SEMACE, no tempo máximo de até 24 horas para realização das análises. Os procedimentos 
analíticos realizados seguiram o Standard Methods for the Examination of Water and Wastewater (APHA et al., 2005).

Os resultados das análises foram comparados com os padrões de potabilidade preconizados pela Portaria No 2.914, de 12 de dezembro de 2011 do Ministério da Saúde (BRASIL, 2011). Os parâmetros físico-químicos analisados, métodos analíticos, reagentes e equipamentos encontramse na Tabela 1.

Tabela 1: Parâmetros analisados, métodos analíticos, reagentes e equipamentos utilizados para avaliar a qualidade físico-química de água subterrânea oriunda de poços da Região Metropolitana de Fortaleza.

\begin{tabular}{|c|c|c|}
\hline Parâmetro & Método Analítico /Reagentes & Equipamentos (Marca/Modelo) \\
\hline $\mathrm{pH}$ & Potenciometria & pHmetro Orion Star -A211 \\
\hline Cor aparente & Colorimetria & Espectrofotômetro HACH- DR 5000 \\
\hline Turbidez & Nefelometria & Turbidímetro HACH -2100Q \\
\hline $\begin{array}{l}\text { Condutividade } \\
\text { Elétrica (CE) }\end{array}$ & Condutivimetria & Sonda multiparamétrica HACH - HQ40d \\
\hline $\begin{array}{l}\text { Sólidos } \quad \text { Totais } \\
\text { Dissolvidos (STD) }\end{array}$ & Condutivimetria & Sonda multiparamétrica HACH - HQ40d \\
\hline Dureza & $\begin{array}{l}\text { Titulação complexométrica com titulante } \\
\text { EDTA e indicador metalocrômio negro de } \\
\text { eriocromo } \mathrm{T} \text {. }\end{array}$ & - \\
\hline Alcalinidade total & $\begin{array}{l}\text { Titulação de neutralização com titulante } \\
\text { solução de ácido sulfúrico }\left(\mathrm{H}_{2} \mathrm{SO}_{4}\right) \\
\text { na presença dos indicadores: fenolftaleína e } \\
\text { solução indicadora verde de } \\
\text { bromocresol/vermelho de metila) }\end{array}$ & - \\
\hline Cálcio $\left(\mathrm{Ca}^{2+}\right)$ & $\begin{array}{l}\text { Titulação complexométrica com titulante } \\
\text { EDTA e indicador metalocrômio murexida. }\end{array}$ & - \\
\hline Magnésio $\left(\mathrm{Mg}^{+}\right)$ & $\begin{array}{l}\text { Cálculo a partir da diferença entre cálcio e } \\
\text { dureza }\end{array}$ & - \\
\hline Cloretos $\left(\mathrm{Cl}^{-}\right)$ & $\begin{array}{l}\text { Titulação argentométrica (Método de } \\
\text { Mohr) com titulante solução padrão de } \\
\text { nitrato de prata }\left(\mathrm{AgNO}_{3}\right) \text { 0,0141N na } \\
\text { presença do indicador cromato de potássio } \\
\left(\mathrm{K}_{2} \mathrm{CrO}_{4}\right) \text {. }\end{array}$ & - \\
\hline Sódio $\left(\mathrm{Na}^{+}\right)$ & Fotometria de chama & Fotômetro Digimed- DM62 \\
\hline Potássio $\left(\mathrm{K}^{+}\right)$ & Fotometria de chama & Fotômetro Digimed- DM62 \\
\hline Nitrito $\left(\mathrm{NO}_{2}^{-}\right)$ & $\begin{array}{l}\text { Colorimetria com reagente NitriVer® } 3 \\
\text { Nitrite Reagent }\end{array}$ & Espectrofotômetro HACH- DR 5000 \\
\hline Nitrato $\left(\mathrm{NO}_{3}^{-}\right)$ & $\begin{array}{l}\text { Colorimetria com reagente NitraVer®5 } \\
\text { Nitrate Reagent }\end{array}$ & Espectrofotômetro HACH- DR 5000 \\
\hline Amônia $\left(\mathrm{NH}_{3}{ }^{+}\right)$ & Colorimetria com reagente Nessler. & Espectrofotômetro HACH- DR 5000 \\
\hline Ferro $\left(\mathrm{Fe}^{2+}\right)$ & $\begin{array}{l}\text { Colorimetria com reagente FerroVer® Iron } \\
\text { Reagent. }\end{array}$ & Espectrofotômetro HACH- DR 5000 \\
\hline Sulfato $\left(\mathrm{SO}_{4}{ }^{2-}\right)$ & $\begin{array}{l}\text { Colorimetria com reagente SulfaVer® } 4 \\
\text { Sulfate Reagent }\end{array}$ & Espectrofotômetro HACH- DR 5000 \\
\hline
\end{tabular}




\section{Resultados e Discussão}

Os resultados das análises das 30 amostras de águas subterrâneas encontram-se nas tabelas 2 e 3 e tiveram como base os padrões de potabilidade estabelecidos pela Portaria $\mathrm{N}^{\mathrm{o}} 2.914$, de 12 de dezembro de 2011 do Ministério da Saúde (BRASIL, 2011).

Tabela 2: Resultados dos parâmetros físico-químicos analisados frente às amostras de água subterrâneas provenientes de poços da Região Metropolitana de Fortaleza - CE, com indicação do valor máximo permitido pela Portaria No 2.914 do Ministério da Saúde (BRASIL, 2011).

\begin{tabular}{|c|c|c|c|c|c|c|c|}
\hline \multirow[b]{2}{*}{ Poços } & \multicolumn{7}{|c|}{ Parâmetros } \\
\hline & pH & $\begin{array}{l}\text { Cor } \\
(\mathbf{u H})\end{array}$ & $\begin{array}{c}\text { Turbidez } \\
\text { (UT) }\end{array}$ & $\begin{array}{c}\mathrm{CE} \\
(\mu \mathrm{S} / \mathrm{cm})\end{array}$ & $\begin{array}{c}\text { STD } \\
(\mathrm{mg} / \mathrm{L})\end{array}$ & $\begin{array}{c}\text { Dureza } \\
(\mathrm{mg} / \mathrm{L} \text { de } \\
\left.\mathrm{CaCO}_{3}\right)\end{array}$ & $\begin{array}{c}\text { Alcalinidade } \\
\text { Total } \\
\text { (mg/L de } \\
\left.\mathrm{CaCO}_{3}\right)\end{array}$ \\
\hline $\mathrm{F} 1$ & 6,3 & $<\mathrm{LD}$ & 0,18 & 533 & 254 & 150 & 22 \\
\hline $\mathrm{F} 2$ & 6,6 & 1 & 0,2 & 506 & 259 & 122 & 54 \\
\hline $\mathrm{F} 3$ & 6,9 & 8 & 0,47 & 293 & 143,9 & 61,4 & 38 \\
\hline $\mathrm{F} 4$ & 6,2 & $125^{*}$ & $12,9 *$ & 651 & 318 & 178,2 & 36 \\
\hline F5 & 6,5 & $205^{*}$ & $22 *$ & 23800 & $13820 *$ & $9128 *$ & 200 \\
\hline F6 & $5,6^{*}$ & 2 & 0,24 & 761 & 370 & 158 & 6 \\
\hline F7 & 6 & 2 & 0,7 & 936 & 417 & 144 & 40 \\
\hline F8 & 6,9 & 9 & 0,67 & 616 & 301 & 96,5 & 114 \\
\hline F9 & 7,38 & $<\mathrm{LD}$ & 0,46 & 567 & 266 & 108,9 & 20 \\
\hline F10 & 6,4 & $977 *$ & $211 *$ & 215 & 103 & 49,5 & 34 \\
\hline F11 & 6,8 & 2 & 2,7 & 503 & 244 & 106,9 & 64 \\
\hline F12 & 6 & $<\mathrm{LD}$ & 0,17 & 115,5 & 54,3 & 24,1 & 20 \\
\hline F13 & 6,84 & 2 & 0,43 & 948 & 465 & 269,66 & 142,71 \\
\hline $\mathrm{F} 14$ & 7,1 & $19^{*}$ & 0,74 & 581 & 283 & 168 & 36,2 \\
\hline F15 & $5,89 *$ & $<\mathrm{LD}$ & 0,26 & 1070 & 529 & 214 & 12,06 \\
\hline $\mathrm{H} 1$ & 6,5 & 15 & 0,28 & 149,8 & 70,7 & 30,1 & 28 \\
\hline $\mathrm{H} 2$ & 7,8 & 4 & 0,74 & 835 & 408 & 76,4 & 228 \\
\hline H3 & 7,9 & 1 & 0,17 & 869 & 429 & 72,4 & 228 \\
\hline A1 & $5,3^{*}$ & 5 & $15,1 *$ & 934 & 459 & 390 & 52 \\
\hline $\mathrm{A} 2$ & 7,4 & 2 & 0,5 & 232 & 110,3 & 12 & 52 \\
\hline A3 & $5,9 *$ & 8 & 1,2 & 133,4 & 62,3 & 15,9 & 8 \\
\hline A4 & 6,2 & $<\mathrm{LD}$ & 0,22 & 319 & 147,9 & 45,5 & 28 \\
\hline A5 & $4,3^{*}$ & 14 & 1,5 & 996 & 492 & 152,5 & 52 \\
\hline A6 & 6,3 & 15 & 2,5 & 93,3 & 46 & 22 & 18 \\
\hline A7 & $5,5^{*}$ & $<\mathrm{LD}$ & 0,5 & 64 & 31 & 10 & 8 \\
\hline A8 & 6,6 & 7 & 0,8 & 87,4 & 37,3 & 15,2 & 14 \\
\hline A9 & 7,9 & $<\mathrm{LD}$ & 0,2 & 463 & 224 & 214 & 188,94 \\
\hline $\mathrm{S} 1$ & 6,5 & $158 *$ & $24,6^{*}$ & 177 & 83,6 & 43,6 & 50 \\
\hline $\mathrm{S} 2$ & 6,2 & $16^{*}$ & 2,6 & 192,8 & 91,6 & 65,3 & 44 \\
\hline E1 & $5,88^{*}$ & 8 & 0,45 & 869 & 427 & 126,63 & 34 \\
\hline VMP & $6,0-9,5$ & $15 \mathrm{uH}$ & $5 \mathrm{UT}$ & - & $\begin{array}{l}1000 \\
\mathrm{mg} / \mathrm{L}\end{array}$ & $\begin{array}{c}500 \\
\mathrm{mg} / \mathrm{L}\end{array}$ & - \\
\hline
\end{tabular}

Legenda: $\mathrm{F}$ = Fortaleza; $\mathrm{H}$ = Horizonte; $\mathrm{A}=$ Aquiraz; $\mathrm{S}$ = São Gonçalo do Amarante; $\mathrm{E}$ = Eusébio; *valores acima do recomendado pela Portaria No 2.914/2011 do Ministério da Saúde (BRASIL, 2011); - = limite máximo não estabelecido pela referida Portaria; $<\mathrm{LD}=$ menor que o limite de detecção; VMP = Valor Máximo Permitido. 
Tabela 3: Resultados das concentrações de cátions e ânions frente às amostras de água subterrâneas provenientes de poços da Região Metropolitana de Fortaleza - CE, com indicação do valor máximo permitido pela Portaria No 2.914 do Ministério da Saúde (BRASIL, 2011).

\begin{tabular}{|c|c|c|c|c|c|c|c|c|c|c|}
\hline \multirow[b]{2}{*}{ Poços } & \multicolumn{10}{|c|}{ Parâmetros } \\
\hline & $\mathrm{Ca}^{2+}$ & $\mathbf{M g}^{+}$ & $\mathrm{Cl}^{-}$ & $\mathrm{Na}^{+}$ & $\mathbf{K}^{+}$ & $\mathrm{NO}_{2}^{-}$ & $\mathrm{NO}_{3}^{-}$ & $\mathrm{NH}_{3}{ }^{+}$ & $\mathrm{Fe}^{2+}$ & $\mathrm{SO}_{4}{ }^{2-}$ \\
\hline $\mathrm{F} 1$ & 40,1 & 12,2 & 120,5 & 72,8 & 11,8 & 0,002 & $28,2 *$ & $<\mathrm{LD}$ & $<\mathrm{LD}$ & 26 \\
\hline $\mathrm{F} 2$ & 26 & 14,1 & 119 & 81,2 & 17 & 0,011 & 8,5 & $2,8^{*}$ & 0,02 & 46 \\
\hline F3 & 7,9 & 10,1 & 75 & 52,3 & 7,2 & 0,002 & 7,6 & $<\mathrm{LD}$ & Zero & 13 \\
\hline $\mathrm{F} 4$ & 42,9 & 17,3 & 149 & 68,3 & 14 & 0,064 & $21,5 *$ & $4,7 *$ & 0,2 & 24 \\
\hline F5 & 992 & 162 & $8376^{*}$ & $2360 *$ & 78,2 & 0,013 & 0,4 & 0,8 & $0,41 *$ & $323 *$ \\
\hline F6 & 24 & 23,8 & 116,6 & 78,4 & 12 & 0,005 & $38 *$ & 0,06 & 0,02 & 17 \\
\hline F7 & 18,3 & 24 & 155 & 90 & 34 & Zero & $15^{*}$ & $<\mathrm{LD}$ & 0,1 & 37 \\
\hline F8 & 10,5 & 17,1 & 99,9 & 91,4 & 12,6 & 0,002 & 0,2 & 0,14 & 0,02 & 17 \\
\hline F9 & 12,7 & 18,8 & 93,5 & 61,1 & 9,6 & 0,002 & $12 *$ & $<\mathrm{LD}$ & 0,02 & 34 \\
\hline F10 & 7,9 & 7,2 & 36,8 & 16,6 & 4,6 & $<\mathrm{LD}$ & 1,9 & 0,7 & $2 *$ & 3 \\
\hline F11 & 19,1 & 14,4 & 63 & 36,9 & 8 & 0,072 & $11,2 *$ & 0,19 & 0,01 & 12 \\
\hline F12 & 1,6 & 4,9 & 21,1 & 12,8 & 0,9 & 0,001 & 0,3 & $<\mathrm{LD}$ & 0,02 & 54,3 \\
\hline F13 & 69,9 & 23,1 & 142,4 & 72 & 7,7 & 0,003 & $22,9 *$ & 0,01 & 0,01 & 11 \\
\hline F14 & 28,9 & 23,4 & 81,7 & 32,9 & 8,2 & 0,003 & $11 *$ & $<\mathrm{LD}$ & 0,02 & 57 \\
\hline F15 & 24,8 & 36,9 & 187,8 & 120 & 9,4 & 0,003 & $44,6^{*}$ & 0,09 & 0,2 & 14 \\
\hline H1 & 3,2 & 5,4 & 14,1 & 16 & 1,3 & 0,003 & 0,6 & $<\mathrm{LD}$ & 0,04 & 16 \\
\hline $\mathrm{H} 2$ & 9,7 & 12,7 & 32,1 & 140 & 11,2 & 0,005 & 0,1 & $<\mathrm{LD}$ & 0,01 & 103 \\
\hline $\mathrm{H} 3$ & 9,7 & 11,7 & 36,7 & 137 & 11,1 & 0,003 & 0,4 & $<\mathrm{LD}$ & 0,04 & 106 \\
\hline $\mathrm{A} 1$ & 68,1 & 10,7 & 150,4 & 96,1 & 12,8 & 0,005 & $46,2^{*}$ & 0,04 & 0,03 & 1 \\
\hline $\mathrm{A} 2$ & 1,6 & 1,9 & 58,4 & 57 & 5,5 & 0,009 & Zero & $<\mathrm{LD}$ & 0,03 & 8 \\
\hline A3 & 2,4 & 2,4 & 29,4 & 16,2 & 2,1 & 0,002 & 1 & 0,03 & 0,13 & 1 \\
\hline A4 & 5,6 & 7,7 & 68,6 & 38 & 4 & 0,003 & 1 & 0,02 & 0,02 & 5 \\
\hline A5 & 37,3 & 14,4 & 201,8 & 120 & 32 & 0,16 & $19,1^{*}$ & 0,09 & 0,06 & 42 \\
\hline A6 & 4 & 2,9 & 19,8 & 14,6 & 2,2 & 0,003 & 1,1 & Zero & 0,1 & 9 \\
\hline A7 & 0,8 & 1,9 & 18,8 & 12,5 & 0,7 & 0,002 & 0,6 & $<\mathrm{LD}$ & 0,1 & 2 \\
\hline A8 & 2,3 & 2,3 & 15,8 & 8,5 & 1,9 & Zero & 1 & $<\mathrm{LD}$ & Zero & 2 \\
\hline A9 & 62,52 & 14,09 & 36,17 & 15,2 & 2,3 & 0,002 & 0,2 & $<\mathrm{LD}$ & Zero & 9 \\
\hline $\mathrm{S} 1$ & 11,9 & 3,4 & 24 & 13,9 & 4,8 & 0,004 & 0,4 & 0,06 & 0,05 & 2 \\
\hline $\mathrm{S} 2$ & 13,5 & 7,8 & 15,1 & 8 & 2,1 & 0,004 & 5,9 & $<\mathrm{LD}$ & 0,05 & Zero \\
\hline E1 & 33 & 10,7 & 208,8 & 117,5 & 2,5 & 0,003 & $53,4^{*}$ & 0,08 & 0,02 & 35 \\
\hline & - & - & $\begin{array}{c}250 \\
\mathrm{mg} / \mathrm{L}\end{array}$ & $\begin{array}{c}200 \\
\mathrm{mg} / \mathrm{L}\end{array}$ & - & $\begin{array}{c}1 \\
\mathrm{mg} / \mathrm{L}\end{array}$ & $\begin{array}{c}10 \\
\mathrm{mg} / \mathrm{L}\end{array}$ & $\begin{array}{c}1,5 \\
\mathrm{mg} / \mathrm{L}\end{array}$ & $\begin{array}{c}0,3 \\
\mathrm{mg} / \mathrm{L}\end{array}$ & $\begin{array}{c}250 \\
\mathrm{mg} / \mathrm{L}\end{array}$ \\
\hline
\end{tabular}

Legenda: $\mathrm{F}=$ Fortaleza; $\mathrm{H}=$ Horizonte; $\mathrm{A}=$ Aquiraz; $\mathrm{S}=$ São Gonçalo do Amarante; $\mathrm{E}=$ Eusébio; *valores acima do recomendado pela Portaria No 2.914/2011 do Ministério da Saúde (BRASIL, 2011); - = limite máximo não estabelecido pela referida Portaria; < LD = menor que o limite de detecção; VMP = Valor Máximo Permitido.

O parâmetro $\mathrm{pH}$ expressa a intensidade de acidez $(\mathrm{pH}<7)$ ou alcalinidade $(\mathrm{pH}>7)$ de uma amostra, por meio da concentração de íons de hidrogênio $\left(\mathrm{H}^{+}\right)$(BRASIL, 2014). A legislação vigente recomenda que o $\mathrm{pH}$ da água destinada para o consumo humano esteja na faixa de 6,0 a 9,5 (BRASIL, 2011). Os valores de $\mathrm{pH}$ da água dos poços amostrados variaram de 4,3 a 7,9. Os poços F6, F15, A1, A3, A5, A7 e E1 apresentaram-se em desacordo com a legislação, uma vez que os valores de $\mathrm{pH}$ obtidos estavam abaixo de 6,0 .

Alterações no $\mathrm{pH}$ de recursos hídricos podem ocorrer naturalmente quando resultantes da dissolução de rochas, absorção de gases atmosféricos, fotossíntese e oxidação da matéria orgânica, ou serem decorrentes da ação antropogênica por meio de despejos domésticos e/ou industrias (VON SPERLING, 2014). 
A cor aparente da água pode ter origem natural a partir da decomposição da matéria orgânica e/ou da presença de metais de ferro e manganês ou origem antropogênica resultado dos despejos de efluentes domésticos e/ou industriais (VON SPERLING, 2014). A cor elevada da água destinada ao consumo humano é esteticamente indesejável (BRASIL, 2013), por isso, a legislação brasileira estabelece o valor máximo de $15 \mathrm{uH}$ para tal parâmetro. Os valores da cor variaram de < LD a 977 uH. Os poços F4, F5, F10, F14, S1 e S2 apresentaram valores acima do permitido.

A turbidez é a medida do grau de redução da intensidade da luz ao atravessar a água, tal redução é gerada pela presença de sólidos em suspensão (CETESB, 2009). O padrão de potabilidade estabelecido para a turbidez é de $5 \mathrm{UT}$, nas amostras analisadas esse parâmetro apresentou valores entre 0,17 a 211 UT. Os poços F4, F5, F10, A1 e S1 estão impróprios para consumo humano uma vez que apresentaram valores superiores ao recomendado.

A condutividade elétrica é a capacidade da água em transmitir corrente elétrica, essa habilidade é resultante da presença de cátions e ânions oriundos de substâncias dissolvidas ou em suspensão que se dissociam na água (OLIVEIRA et al., 2014). O Ministério da Saúde não estabelece valor limite para esse parâmetro, os resultados encontrados nas amostras variaram de 64 a $23800 \mu \mathrm{S} / \mathrm{cm}$.

O padrão de potabilidade preconizado para os sólidos totais dissolvidos é de no máximo $1.000 \mathrm{mg} / \mathrm{L}$. Os valores de sólidos totais dissolvidos nas amostras estiveram entre 31 a 13.820 mg/L, apenas o poço F5 apresentou-se em desconformidade com o limite preconizado. Os sólidos totais dissolvidos correspondem às partículas de diâmetro inferior a $10^{-3} \mu \mathrm{m}$ e são tidos como padrão de potabilidade uma vez que sua presença possui associação com despejos de esgotos, além de causar alteração na qualidade organoléptica da água, o que leva a rejeição da mesma por parte do consumidor (BRASIL, 2006).

O padrão de potabilidade para dureza total é de máximo $500 \mathrm{mg} / \mathrm{L}$ de $\mathrm{CaCO}_{3}$, os resultados obtidos variaram de 10 a $9.128 \mathrm{mg} / \mathrm{L}$ de $\mathrm{CaCO}_{3}$. Apenas o poço $\mathrm{F} 5\left(9128 \mathrm{mg} / \mathrm{L}\right.$ de $\left.\mathrm{CaCO}_{3}\right)$ apresentou resultado superior ao limite estabelecido, estando sua água na classificação de muito dura. A dureza é resultante principalmente da concentração dos íons de cálcio e magnésio na água e é expressa em $\mathrm{mg} / \mathrm{L}$ de carbonato de cálcio $\left(\mathrm{CaCO}_{3}\right)$ (POHLING, 2009). A dureza total não possui significado em termos sanitários, e em função do seu valor a água pode ser classificada em: mole ou branda $\left(<50 \mathrm{mg} / \mathrm{L}\right.$ de $\mathrm{CaCO}_{3}$ ), dureza moderada $\left(50\right.$ - $150 \mathrm{mg} / \mathrm{L}$ de $\left.\mathrm{CaCO}_{3}\right)$, dura (150 $300 \mathrm{mg} / \mathrm{L}$ de $\mathrm{CaCO} 3$ ) e muito dura (> $300 \mathrm{mg} / \mathrm{L}$ de $\mathrm{CaCO} 3$ ) (LIBÂNEO, 2016).

Em águas provenientes de recursos hídricos subterrâneos os íons de cálcio e magnésio são encontrados geralmente na faixa de 2 a $200 \mathrm{mg} \mathrm{Ca}{ }^{2+} / \mathrm{L}$ e de 1 a $40 \mathrm{mg}^{2+} / \mathrm{L}$, respectivamente (POHLING, 2009). Nas amostras de poços analisadas os teores encontrados de cálcio variaram de 0,8 a $992 \mathrm{mg} / \mathrm{L}$ e os de magnésio de 1,9 a $162 \mathrm{mg} / \mathrm{L}$. A legislação brasileira não estabelece padrões para cálcio e magnésio.

A alcalinidade total da água é resultante da presença de carbonatos $\left(\mathrm{CO}_{3}{ }^{-2}\right)$, bicarbonatos $\left(\mathrm{HCO}_{3}{ }^{-}\right)$e hidróxidos $\left(\mathrm{OH}^{-}\right)$, e expressa a capacidade da água em neutralizar ácidos (SANTOS; MOHR, 2013). Os valores de alcalinidade variaram de 6 a $228 \mathrm{mg} / \mathrm{L} \mathrm{de} \mathrm{CaCO}_{3}$, para tal parâmetro a Portaria 2.914/2011 não estabelece valor máximo permitido.

Os cloretos quando encontrados em teores elevados conferem a água sabor salgado e possuem efeitos laxativos, tais íons podem ter origem natural (dissolução de minerais ou intrusão de águas marinhas) ou antropogênica (esgotos domésticos e industriais) (BRASIL, 2014). O valor máximo permitido para concentrações de cloretos em águas destinadas ao consumo humano é de $250 \mathrm{mg} / \mathrm{L}$. Com resultados que variaram de 14,1 a $8.376 \mathrm{mg} / \mathrm{L}$, observou-se que apenas o poço F5 apresentou teor acima do permitido. Costa et al. (2012) obtiveram resultado semelhante ao avaliar a qualidade das águas subterrâneas em poços do estado do Ceará, identificando que apenas 1,7\% das amostras estavam acima do limite máximo permitido pela legislação vigente.

De acordo com a CETESB (2009), o sódio está presente em todas as águas naturais, sendo encontrado frequentemente em concentrações que excedem $50 \mathrm{mg} / \mathrm{L}$ em recursos hídricos 
subterrâneos. A CETESB ainda afirma que teores elevados de sódio podem ser provenientes de esgotos domésticos, efluentes industriais ou intrusão de águas marinhas em regiões litorâneas. $\mathrm{O}$ padrão de potabilidade para o sódio é de no máximo $200 \mathrm{mg} / \mathrm{L}$, dos teores encontrados nas amostras (8 a $2.360 \mathrm{mg} / \mathrm{L}$ ) apenas o poço F5 apresentou-se em desacordo, estando mais que 11 vezes acima do padrão permitido. Diferentemente do sódio, o potássio é encontrado na água em menor concentração, sendo que em águas subterrâneas ocorre em pequena quantidade ou pode até estar ausente, uma vez que é um elemento que realiza intensa troca iônica e que também é facilmente incorporado aos minerais e vegetais (MAZZINI, 2012). A Portaria 2.914/2011 não estabelece padrão de potabilidade para a concentração de potássio, nas amostras essas concentrações apresentaram-se entre 0,7 a $78,2 \mathrm{mg} / \mathrm{L}$.

A amônia é comumente encontrada em baixa concentração em recursos hídricos subterrâneos, devido sua capacidade de aderir-se a partículas do solo (SILVA; OLIVEIRA, 2001). Neste estudo os teores de amônia estiveram na faixa de $<\mathrm{LD}$ a $4,7 \mathrm{mg} / \mathrm{L}$, para esse parâmetro a legislação brasileira recomenda como valor máximo permitido de $1,5 \mathrm{mg} / \mathrm{L}$, desta forma observouse que só os poços F2 e F4 apresentaram-se acima do permitido.

O nitrito é a forma intermediária entre a amônia e o nitrato, e quando encontrado em teores elevados pode acarretar a metahemoglobinemia (GADELHA et al., 2005). O padrão de potabilidade para o nitrito é de no máximo $1,0 \mathrm{mg} / \mathrm{L}$ e os teores encontrados em todas as amostras $(<\mathrm{LD}$ a $0,16 \mathrm{mg} / \mathrm{L})$ apresentaram-se de acordo como o padrão recomendado. $\mathrm{O}$ íon nitrato é naturalmente encontrado em águas subterrâneas em teores que variam de 0,1 a $10 \mathrm{mg} / \mathrm{L}$, sendo que em casos de contaminações podem atingir teores de $1.000 \mathrm{mg} / \mathrm{L}$, tal íon devido as suas características de alta mobilidade e persistência em águas subterrâneas é mundialmente utilizado como indicador de contaminação (CETESB, 2007).

Em áreas urbanas a disposição inadequada do esgoto doméstico em fossa rudimentar ou até mesmo vazamentos das redes coletoras de esgoto são os principais responsáveis pela contaminação da água subterrânea por nitrato (VARNIER, 2010). O consumo de água com elevados teores de nitrato pode acarretar doenças como metahemoglobinemia em recém-nascidos e adultos (no caso destes quando há deficiência enzimática) e câncer de estômago (SILVA; BROTTO, 2014). Elevados teores dos íons nitrato e nitrito são indicativos de poluição antiga, já a amônia indica poluição recente (LIBÂNEO, 2016). O Ministério da Saúde recomenda para o íon nitrato o padrão máximo permitido de $10 \mathrm{mg} / \mathrm{L}$, nas águas de poços amostrados neste estudo os teores encontrados foram de 0 a 53,4 mg/L. Os poços F1, F4, F6, F7, F9, F11, F13, F14, F15, A1, A5 e E1 estão acima como padrão recomendado. Costa et al. (2011) em pesquisa para avaliar a qualidade das águas subterrâneas a sudoeste de Fortaleza - CE, constataram que das 14 amostras de poços analisadas, $12(86 \%)$ apresentaram-se acima do padrão recomendado.

O íon ferro em águas subterrâneas é naturalmente encontrado em concentrações abaixo de 0,3 mg/L (KEMERICH et al., 2012), quando em concentrações elevadas conferem cor e sabor a água (CETESB, 2009). Os teores do íon ferro variaram de $<\mathrm{LD}$ a $2 \mathrm{mg} / \mathrm{L}$, para esse íon a legislação vigente estabelece como padrão de potabilidade teores de no máximo $0,3 \mathrm{mg} / \mathrm{L}$, desta forma os poços F5 e F10 apresentaram valores acima do recomendado. Geralmente, teores elevados do íon ferro em águas subterrâneas de Fortaleza ocorrem devido a presença desse íon nos solos lateríticos do Aquífero Barreiras (COSTA et al., 2011).

Em águas naturais os teores de sulfato variam de 2 a $80 \mathrm{mg} / \mathrm{L}$ (BECKER, 2008), sendo estabelecido o padrão de potabilidade de $250 \mathrm{mg} / \mathrm{L}$. Águas com teores acima do padrão estabelecido além de apresentarem sabor desagradável, quando consumidas continuamente provocam desidratação e irritação gastrointestinal (ARRUDA et al., 2012). Com teores de sulfato que variaram de 0 a $323 \mathrm{mg} / \mathrm{L}$, apenas o poço F5 apresentou teor acima do limite estabelecido.

\section{Considerações Finais}


Os resultados das análises físico-químicas revelaram que da totalidade de 30 amostras de águas subterrâneas oriundas de poços de algumas cidades da Região Metropolitana de FortalezaCE, 19 (63,33\%) estão impróprias para consumo humano conforme os limites de potabilidade preconizados pela Portaria 2.914/11 do Ministério da Saúde (BRASIL, 2011).

Os parâmetros físico-químicos que se apresentaram em desacordo foram $\mathrm{pH}$, cor, turbidez, sólidos totais dissolvidos, dureza, cloreto, sódio, amônia, nitrato, ferro e sulfato. Sendo, o mais alarmante, o parâmetro nitrato que das 19 amostras em desacordo esteve acima do padrão em 12 amostras $(63,15 \%)$. Teores elevados de nitrato em aglomerados urbanos são associados principalmente à contaminação do lençol freático por esgotos domésticos.

Alerta-se para a importância do monitoramento frequente da qualidade físico-química da água subterrânea da Região Metropolitana de Fortaleza - CE, uma vez que alguns dos parâmetros em desacordo com a legislação vigente acarretam danos à saúde pública ou conferem a água propriedades organolépticas indesejadas. Bem como, os dados apresentados visam auxiliar no panorama da qualidade de água subterrânea da Região Nordeste e, por conseguinte, na garantia da potabilidade das águas subterrâneas na perspectiva nacional.

\section{Referências}

ALBUQUERQUE FILHO, J. L.; BARBOSA, M. C.; AZEVEDO, S. G. de; CARVALHO, A. M. de. O papel das águas subterrâneas como reserva estratégica de água e diretrizes para a sua gestão sustentável. Revista de Recursos Hídricos, Lisboa, v. 32, n. 2, p. 53-61, 2011.

APHA/AWWA/WEF. Standard methods for the examination of water and wastewater. 21. ed. Washington: American Public Health Association, 2005.

ARRUDA, G. B.; CORREIA, K. V.; MENOR, E. A.; LINS, V. Contaminações em sulfato e cloretos em águas de superfície e subsuperfície na região de Araripina-Pe. Estudos Geológicos, v. 22 (2), p. $149-171,2012$.

BECKER, H. Controle analítico de águas. Fortaleza - CE, Versão 4. 2008, p. 46.

BRASIL. Fundação Nacional de Saúde. Manual prático de análise de água. 4. ed. Brasília: FUNASA, 2013.

Ministério do Meio Ambiente. Secretaria de Recursos Hídricos e Ambiente Urbano. Águas subterrâneas. Um recurso a ser conhecido e protegido. Brasília: MMA/SRH, 2007.

Ministério da Saúde. Fundação Nacional de Saúde. Manual de controle da qualidade da água para técnicos que trabalham em ETAS. Ministério da Saúde, Fundação Nacional de Saúde. Brasília: Funasa, 2014.112p.

Ministério da Saúde. Secretaria de Vigilância em Saúde. Portaria no 2.914 de 12 de dezembro de 2011. Dispõe sobre os procedimentos de controle e de vigilância da qualidade da água para consumo humano e seu padrão de potabilidade. Diário Oficial da União, Seção 1, p. 266, 16 dez. 2011.

. Ministério da Saúde. Secretaria de Vigilância em Saúde. Vigilância e controle da qualidade da água para consumo humano. Brasília: Ministério da Saúde, 2006. 212p.

CEARÁ. Índices de Cobertura, 2017. Disponível em: http: // www. cagece. com.br /numeros/ indice- de- cobertura. Acesso: 30 de jun. de 2017. 
Instituto de Pesquisa e Estratégia Econômica do Ceará- IPECE. Perfil das regiões de planejamento: Grande Fortaleza - 2016. Fortaleza: IPECE, 2016.

CETESB - COMPANHIA AMBIENTAL DO ESTADO DE SÃO PAULO. Guia nacional de coleta e preservação de amostras: água, sedimento, comunidades aquáticas e efluentes líquidos. São Paulo: CETESB; Brasília: ANA, 2011.

CETESB - COMPANHIA AMBIENTAL DO ESTADO DE SÃO PAULO. Qualidade das águas interiores no Estado de São Paulo. Série de relatórios - Apêndice A: Significado ambiental e sanitário das variáveis de qualidade das águas e dos sedimentos e metodologias analíticas e de amostragem. São Paulo: CETESB, 2009.

CETESB - COMPANHIA AMBIENTAL DO ESTADO DE SÃO PAULO. Relatório das águas subterrâneas do Estado de São Paulo: 2004-2006. São Paulo: CETESB, 2007.

COSTA, C. L.; LIMA, R. F. L.; PAIXÃO, G. C.; PANTOJA, L. D. M. Avaliação da qualidade das águas subterrâneas em poços do estado do Ceará, Brasil. Semina: Ciências Biológicas e da Saúde, Londrina, v. 33, n. 2, p. 171-180, 2012.

COSTA, S. A.; CAVALCANTE, I. N.; GOMES, M. C. R.; ALMEIDA, N. M.; OLIVEIRA, M. R. B. Qualidade das águas subterrâneas freáticas a Sudoeste de Fortaleza, Ceará - Brasil. In: CONGRESSO INTERNACIONAL DE MEIO AMBIENTE SUBTERRÂNEO, 2., 2011, São Paulo. Anais ... ABAS, 2011. p. 4.

GADELHA, F. J. S.; DOMINGOS, M. S. C.; NOGUEIRA, M. F. L.; SILVA, M. L. L.; MACEDO, R. E. F.; SOUZA, G. C.; NESS, R. L. L. Verificação da presença de nitrito em águas de consumo humano da comunidade de Várzea do Cobra em Limoeiro do Norte-CE. In: REUNIÃO ANUAL DA SBPC, 57., Fortaleza. Anais... Fortaleza: UECE, 2005. p. 2.

HIRATA, R.; VIVIANI-LIMA, J.B.; HIRATA, H. A água como recurso. In: TEIXEIRA, W.; FAIRCHILD, T. R.; TOLEDO, M. C. M.; TAIOLI, F. (Org.). Decifrando a terra. 2. ed. São Paulo: Companhia Editora Nacional, 2009. Cap. 17. p.448-485.

IBGE - INSTITUTO BRASILEIRO DE GEOGRAFIA E ESTATÍSTICA. Pesquisa Nacional por Amostra de Domicílios: síntese de indicadores 2015. Rio de Janeiro: IBGE, 2016. 108p.

KEMERICH, P. D. C.; SILVA, J. L. S.; BARROS, G.; BORBA, W. F.; UCKER, F. E.; FOLETTO, C. V. Caracterização química da água subterrânea em área ocupada por cemitério: uso da técnica de espectrometria de fluorescência de raios-X por energia dispersiva (EDXRF). Revista Ambiente \& Água, Taubaté, v.7, n.3, p.166 - 182, 2012.

LIBÂNEO, M. Fundamentos de qualidade e tratamento de água. 4. ed. Campinas: Editora Átomo, 2016.

LIMA, R. B.; OLIVEIRA, D.S.; DI SOUZA, L.; BATISTA, R. O.; ALVES, S. M. C.; SILVA, F. U. Análise físico-química da água de três poços subterrâneos no município de Mossoró-RN. Revista Química: ciência, tecnologia, e sociedade, Mossoró, v. 4. n. 2, p. 9-23, 2015. 
LÖBLER, C. A. Análise da vulnerabilidade à contaminação das águas subterrâneas do município de nova palma, RS. 2013. 52 f. Monografia (Bacharelado em Geografia) Universidade Federal de Santa Maria, Santa Maria. 2013.

MAZZINI, F. Hidrogeoquímica do aquífero Bauru na área urbana do município de Marília (SP). 2012. 56 f. Dissertação (Mestrado em Engenharia Civil e Ambiental) - Universidade Estadual Paulista, Bauru - SP, 2012.

OLIVEIRA, K. B. M.; MORAIS, F.; BACELLAR, L. A. P. Distribuição de parâmetros hidroquímicos das águas subterrâneas na região da Lagoa da Confusão - TO - Brasil. Ambiência, Guarapuava, v. 10, s. 1. p. 282- 302, 2014.

POHLING, R. Reações químicas na análise de água. Fortaleza: Editora Arte Visual, 2009.

SAMPAIO, T. Q.; FEITOSA, F. A. C. Atuação governamental no abastecimento de água subterrânea no semiárido nordestino: o sistema SIAGAS e as possibilidades de revitalização de poços. In: CONGRESSO RESAG ENQUALAB, 14., 2014, São Paulo. Anais... São Paulo: RESAG, 2014.

SANTOS, R. S.; MOHR, T. Saúde e qualidade da água: análises microbiológicas e físico-químicas em águas subterrâneas. Revista contexto \& Saúde, IJUÍ, v. 13, n. 24-25. p. 46-53, 2013.

SILVA, D. D. da.; MIGLIORINI, R. B.; SILVA, E. de C. e.; LIMA, Z. M de.; MOURAS, I. B de. Falta de saneamento básico e as águas subterrâneas em aquífero freático: região do Bairro Pedra Noventa, Cuiabá (MT). Engenharia Sanitária e Ambiental, Rio de Janeiro, v. 19, n. 1, p 43-52, 2014.

SILVA, L. C. M.; BROTTO, M. E. Nitrato em água: ocorrência e consequência. 2014. Disponível em: < http://www.creasp.org.br/biblioteca/teses_e_artigos/nitrato-em-aguaocorrencia-e-consequencias/ >. Acesso em: 18 maio. 2018.

SILVA, S.A.; OLIVEIRA, R. de. Manual de análises físico-químicas de águas de abastecimento e residuárias. Campina Grande, Paraíba: O Autor, 2001.

VARNIER, C.; IRITANI, M. A.; VIOTTI, M.; ODA, G. H.; FERREIRA, L. M. R. Nitrato nas águas subterrâneas do sistema aquífero Bauru, área urbana do município de Marília (SP). Revista do Instituto Geológico, São Paulo, v. 3. n. 1-2, p. 1-21, 2010.

VON SPERLING, M. Introdução à qualidade das águas e ao tratamento de esgotos. 4. ed. Belo Horizonte: UFMG, 2014.

WHATELY, M.; CAMPANILI, M. O século da escassez. Uma nova cultura de cuidado com a água: impasses e desafios. 1. ed. São Paulo: Claro Enigma, 2016. 